\title{
FIELD TRIALS TO EVALUATE THE RELEASE OF THE PREDATORY MITE Phytoseiulus persimilis A. - H. AND THE LADY BUG Stethorus gilvifrons MULSANT IN SUPPRESSING THE POPULATION OF Tetranychus urticae infesting BEAN PLANTS.
}

Nassar, O. A.; A. H. Fouly and M. A. Osman

Agricultural Zoology Department, Faculty of Agriculture, Mansoura University, Mansoura 35516, Egypt.

\begin{abstract}
Field trials were conducted at the farm of the faculty of agriculture, Mansoura University in order to evaluate the efficacy of the predatory mite $P$. persimilis and the predatory insect $S$. gilvifrons in suppressing the population of the two spotted spider mite $T$. urticae after release of the predacious arthropods in open field cultivated with green beans. Three suggested levels of the predator : prey ratio were used, namely 1:20, 1: 40and 1:60 for both predacious arthropods. The percent reduction in egg stages of $T$. urticae at the first level was 76.17 and 85.5 for the predatory mite and insect respectively after 25 day of release. While the present reduction in moving stages of $T$. urticae at the first level was 78.28 and 84.97 for the predatory mite and insect respectively after the same period of the release.
\end{abstract}

\section{INTRODUCTION}

High reproduction rates along with rapid developmental times give spider mites, especially the two spotted spider mite Tetranychus urticae, the potential for population outbreaks that can cause sever economic damage.

This potentiality of spider mites gives the biological control a great attention especially the ability of these pests to acquire resistance to acaricides (Sabelis, 1981 and Geoghiou, 1990). Also, as reported before by several researchers that phytoseiid mites and the coccinellid beetles are the most important predators as biological control agents all over the world (Gerson and smiley, 1990; Gilstrap, 1995; McMurtry and Croft, 1997; Osman, 2000; Kishimoto, 2003 and Roy et al. 2003).

Therefore, it was necessary to evaluate the role of exotic predatory mite $P$. persimilis under the field condition in Egypt. Also, evaluate the role of $S$. gilvifrons, as one of the most dominant and obligate predators of tetranychid mites in Egypt, in suppressing $T$. urticae populations infesting bean plants under field condition at Mansoura district.

\section{MATERIALS AND METHODS}

\section{Release Technique}

The experiment was carried out during 2003, at the farm of the Faculty of Agriculture, Mansoura University. Trials were done in seven plots, 
each plot $8 \times 9 \mathrm{~m}$. The plots were cultivated with green beans Phaseolus vulgaris and left one month for growing up without any mite infestation. Each plot was considered a treatment, where the first one was a control and the other six were represented levels of release.

Pure cultures of the predatory mite $P$. persimilis were reared using methods modified from (McMurty and Scriven, 1965). Pure cultures of the predatory coccinellid S. gilvifrons kept in plastic boxes $20 \mathrm{~cm} \times 10 \mathrm{~cm} \times 5 \mathrm{~cm}$ covered with muslin on the top and the bottom covered with filter paper. The boxes were provided with pieces of leaves of castor plants heavily infested with spider mites $T$. urticae as a food source.

Five plants in each plot were used as a replicate that artificially infested with leaves of Ricinus communis heavily infested with the spider mites $T$. urticae. Each plant was caged individually under muslin $120 \mathrm{~cm} \times 50 \mathrm{~cm}$ and represent a replicate was repeated five times for each treatment.

Spider mite populations were left to increase for twenty days in the field. After that, all stages of spider mites were counted on plant leaf samples (3 leaves / plant or 9 leaflets / plant). The predatory mite $P$. persimilis was released in three levels to evaluate their effectiveness in controlling $T$. urticae infesting bean plants under field conditions. The suggested predator : prey ratio $1: 20 . \quad 1: 40,1: 60$, respectively . On other hand, the same levels were used with the predatory coccinellid $S$. gilvifrons. The control plot remained free without predatory mites or coccinellids.

Predatory mites and insects prepared for release process were kept in the incubator under temperature of $10^{\circ} \mathrm{C}$ for 5 minutes to eliminate mite and coccinellid activity in order to help for their handling. Female predatory mites and insects were transferred to discs of castor plant and then inserted inside tubes. The tubes were closed by a piece of muslin to prevent mite and coccinellid from escaping. All tubes prepared for release were put in ice box to keep the mites and coccinellids inactive till transferring them to the field. The release was carried out 1-2 hours before sunset and 2-3 days after crop irrigation to warrant suitable air temperature and relative humidity for introduction of predatory.

Samples of three leaves (9 leaflets) from each plant under cages were randomly taken from each plot after regular intervals of 5 days and continuously up to 25 days. Colleted samples were carefully transferred to the laboratory inside cellophane bags with small pieces of cotton wool soaked in ether. These samples were directly inspected under stereoscopic binocular microscope to estimate living and consumed individuals of $T$. urticae at different levels of the predatism of $P$. persimilis and S. gilvifrons. Any stages of the predatory mites and coccinellids were collected carefully and placed on bean plant. The predators efficiency was determined and evaluated where Data were statically analyzed using Henderson and Tilton formula (1955).

\section{RESULTS AND DISCUSSION}

Data listed in Table (1) showed that release $P$. persimilis at levels $1: 20,1: 40$ and $1: 60$, respectively caused reduction percentages of eggs 
of $T$. urticae $58.41 \%, 51.57 \%$ and 42.67 after 5 days, while these percentages were $65.48 \%, 59.19 \%$ and 53.78 , for S. gilvifrons release at 1 : $20,1: 40$ and $1: 60$, respectively.

After 10 days from release the reduction percentages of eggs of $T$. urticae were $61.04 \%, 56.90$ and 48.14 , respectively for predatory mite and $72.50 \%, 66.85 \%$ and $57.64 \%$ for S. gilvifrons at the same previous levels respectively.

Moreover, after 15 days the reduction percentages of eggs of $T$. urticae were $65.82 \%, 62.70 \%$ and 53.48 by $P$. persimilis at levels $1: 20,1$ : 40 and $1: 60$, respectively. On the other hand the reduction percentages by S. gilvifrons were $76.41 \%, 71.02 \%$ and $63.36 \%$ at levels $1: 20,1: 40$ and $1: 60$, respectively. 20 days after release Data in Table (1) showed that the $P$. persimilis and S. gilvifrons caused the reduction percentages of eggs of $T$. urticae to be $72.76 \%, 67.56 \%, 58.90$ and $81.41 \%, 75.43 \%, 69.50 \%$ at the aforementioned release levels, respectively.

After 25 days reduction percentages of $T$. urticae eggs increased to $76.17 \%, 72.15 \%$ and $66.52 \%$ by P. persimilis and $85.00 \%, 79.50 \%$ and $71.34 \%$ at the three levels, respectively. From the previous results, it was noticed that the reduction percentages of eggs of $T$. urticae by $P$. persimilis after $5,10,15,20$ and 25 days was $58.41 \%, 61.04 \%, 65.82 \%, 72.76 \%$ and $76.17 \%$ at $\mathrm{T}_{1} ; 51.57 \%, 56.90 \%, 62.70 \%, 67.56$ and $72.15 \% \mathrm{~T}_{2}$ and 42.67 $\%, 48.14 \%, 53.48 \%, 58.90 \%$ and $66.52 \%$, at $\mathrm{T}_{3}$ respectively. Table (1)

\begin{tabular}{|c|c|c|c|c|c|}
\hline \multirow[t]{3}{*}{ Day } & \multicolumn{5}{|c|}{ Time after release ( days ) } \\
\hline & 5 & 10 & 15 & 20 & 25 \\
\hline & $\%$ Reduction & \% Reduction & $\%$ Reduction & $\%$ Reduction & $\%$ Reduction \\
\hline & \multicolumn{5}{|c|}{ P. persimilis } \\
\hline T1 $(1: 20)$ & 58.41 & 61.04 & 65.82 & 72.76 & 76.17 \\
\hline T2 $(1: 40)$ & 51.57 & 56.90 & 62.70 & 67.56 & 72.15 \\
\hline T3 $(1: 60)$ & 42.67 & 48.14 & 53.48 & 58.90 & 66.52 \\
\hline & \multicolumn{5}{|c|}{ S. gilvifrons } \\
\hline T4 $(1: 20)$ & 65.48 & 72.50 & 76.41 & 81.41 & 85.00 \\
\hline T5 $(1: 40)$ & 59.19 & 66.85 & 71.02 & 75.43 & 79.50 \\
\hline T6 $(1: 60)$ & 53.78 & 57.64 & 63.36 & 69.50 & 71.34 \\
\hline
\end{tabular}

Reduction percentages of eggs of $T$. urticae by $S$. gilvifrons and after $5,10,15,20$ and 25 days were $65.48 \%, 72.50 \%, 76.41 \%, 81.41 \%$ and 85.00 at T4 and $59.19 \%, 66.85 \%, 71.02 \%, 75.43 \%$ and $79.50 \%$ T5 and $53.78 \%, 57.64 \%, 63.36 \%, 69.50 \%$ and $71.34 \%$, at T6 respectively.

On the other hand Data in Table (2) showed that relase $P$. persimilis at levels $1: 20,1: 40$ and $1: 60$, respectively caused reduction percentages of moving stages of T. urticae $58.09 \%, 53.90 \%$ and $45.20 \%$ after 5 days, while these percentages were $64.10 \%, 56.92 \%$ and $52.31 \%$, respectively when released $S$. gilvifrons at $1: 20,1: 40$ and $1: 60$, respectively. 
After 10 days from release the reduction percentages of moving stages of $T$. urticae were $65.07 \%, 61.58 \%$ and $52.16 \%$, respectively when using $P$. persimilis at levels $1: 20,1: 40$ and $1: 60$, respectively. Also, S. gilvifrons caused reduction percentages of moving stages of T. urticae $69.04 \%, 65.47 \%$ and $60.98 \%$ at the same previous levels respectively.

Moreover, after 15 days the reduction percentages of moving stages of T. urticae were $69.42 \%, 66.08 \%$ and $58.63 \%$ by P. persimilis at levels $1: 20,1: 40$ and $1: 60$, respectively. On the other hand the reduction percentages by S. gilvifrons were $75.41 \%, 70.39 \%$ and $67.22 \%$ at levels $1: 20,1: 40$ and $1: 60$, respectively.

20 days after release Data in Table (2) showed that the $P$. persimilis and $S$. gilvifrons caused the reduction percentages of $T$. urticae moving stages $73.71 \%, 70.01 \%, 64.07 \%$ and $82.34 \%, 76.99 \%, 70.25 \%$ at levels $1: 20,1: 40$ and $1: 60$, respectively.

Table (2) : Reduction Percentage ( \%) of Tetranychus urticae moving stages of infesting bean plants after releasing different levels of Phytoseiulus persimilis (Athias-Henriot) and Stethorus gilvifrons (Muslant)

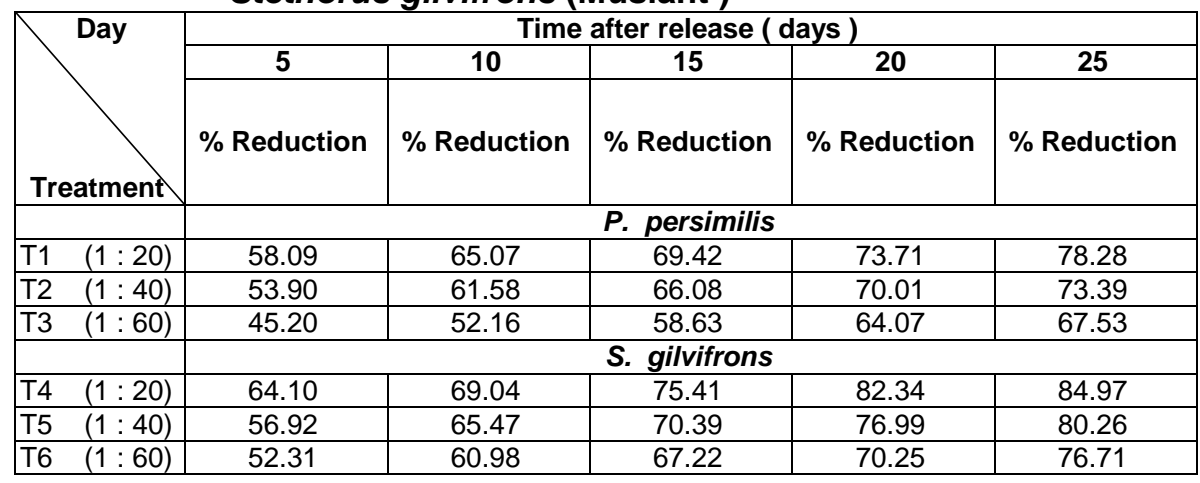

After 25 days the reduction percentages of moving stages of T. urticae increased to $78.28 \%, 73.39 \%$ and 67.53 by $\boldsymbol{P}$. persimilis at levels (T1) $1: 20$, (T2) $1: 40$ and (T3) $1: 60$, respectively and $84.97 \%$, $80.26 \%$ and $76.71 \%$ at levels $1: 20,1: 40$ and $1: 60$, for S. gilvifrons respectively.

In the other words, the reduction percentages of moving stages of $\boldsymbol{T}$. urticae by $\boldsymbol{P}$. persimilis at T1 (1 predator : 20 prey) after 5, 10, 15, 20 and 25 days were $58.09 \%, 65.07 \%, 69.42 \%, 73.71 \%$ and $78.28 \%$, respectively; at T2 (1 predator : 40 prey) $53.90 \%, 61.58 \%, 66.08 \%, 70.01$ and $73.39 \%$ and at T3 (1 predator : 60 prey) $45.20 \%, 52.16 \%, 58.63 \%$, $64.07 \%$ and $67.53 \%$, respectively.

Moreover, reduction percentages of $\boldsymbol{T}$. urticae eggs by $\boldsymbol{S}$. gilvifrons at T4 (1 predator : 20 prey) and T5 (1 predator : 40 prey) after 5, 10, 15,20 and 25 days were $64.10 \%, 69.04 \%, 75.41 \%, 82.34 \%$ and $84.97 \%$ and $56.92 \%, 65.47 \%, 70.39 \%, 76.99 \%$ and $80.26 \%$, respectively. At T6 
(1 predator : 60 prey) was $52.31 \%, 60.89 \%, 67.22 \%, 70.25 \%$ and 76.71 $\%$, respectively.

Similar results were obtained by Ho (1990) who used $A$. fallacis and $P$. persimilis that gave effective control of Tetranychus kanzawai after introduction onto potted tea plants at a ratio of 1:20 in a greenhouse. On the 10 th and 14th day after release, the percentage control by $N$. fallacis was 72.8 and 88.6, resp., while that by $P$. persimilis was 84.0 and 99.1 . In field trials in Taiwan, both predators, but especially $P$. persimilis, reduced the numbers of $T$. kanzawai to less than one mite/leaf.

Also, Bonomo (1991) stated that release of $P$. persimilis gave effective control of the mite T. urticae at ratio 1:10. Moreover, Chermiti (1992) found that One release of $P$. persimilis at a rate of one predator for $10 \mathrm{~T}$. urticae was sufficient to control a pest population. The population of $T$. urticae was reduced in 3 weeks and completely eliminated in 7 weeks.

On the other hand Campbell and Lilley (1999) showed that P. persimilis decreased $T$. urticae when the prey: predator ratio reached approximately 10:1. when release on two varieties of dwarf hops.

Similar results were obtained by Opit et al. (2004) who found that $P$. persimilis significantly reduced $T$. urticae populations 1 week after release at ratios of 1:4 and 1:20, on ivy geraniums and kept them at low levels thereafter.

As concering, lady bug S. gilvifrons Jiang et al. (1982) showed that the Stethorus punctillum (Weise), an important predator of tetranychid mites, and its effectiveness in controlling cotton pests. When the predator was released in cotton fields, percentage control of tetranychids was lasted for 18 days. The best predator : prey ratio for control was $1: 130$.

Moreover, Huang et al. (1988) stated that the coccinellid Stethorus siphonulus Kapur was suppressed the number of Panonychus citri. In citrus orchards when released predator at densities of 20-40 individuals/tree and that is agree with previous results. Also, (Shimoda et al.,1993; Ehara and Shinkaji, 1996; Gotoh and Gomi, 2000; Kishimoto,2002; Kitashima and Gotoh, 2003).were found Stethorus japonicus Kamiya suppressed $T$. urticae and the T. kanzawai in fields of apple, citrus, tea, pear, hydrangea and kudzu vine.

From the previous results it can be conclude that $P$. persimilis, is one of the most dominant exotic phytoseiid mites in Egypt, which may play an important role as an effective factors for reducing the population of the two spotted spider mite beside other factors in IPM scheme. Also, lady bug $S$. gilvifrons belonging to the genus Stethorus is obligate predator of tetranychid mites. Therefore, it is highly recommended to play an important role for supressing T. urticae in open field and under greenhouse. From the previous results the predatory mite and insect under investigation are promising as biological control agents of spider mite and there is feasibility of using it in the IPM programmes. 


\section{REFERENCES}

Bonomo, G.; Catalano, G.; Maltese, V. and Sparta, S. (1991).Biological and integrated control experiments in Marsalese strawberry crops. ( Italian).Informatore Agrario. 1991. 47: 12, 97-100.

Campbell, C. A. M. and Lilley, R. (1999). The effects of timing and rates of release of Phytoseiulus persimilis against two-spotted spider mite Tetranychus urticae on dwarf hops.Biocontrol Science and Technology. 9: 4, 453-465.

Ehara, S. and Shinkaji, N. (1996). Principles of Plant Acarology.ZenkokuNoson-Kyoiku-Kyokai, Tokyo, Japan. 419 p. (in Japanese).

Gerson, U. and Smiley, R.L. (1990). Acarine Biological Agents. Chapman and Hall, London. 174p.

Gilstrap, F. E. (1995). Six-spotted thrips: a gift from nature that controls spider mites. In Thrips Biology and Management(B. L. Parker, M. Skinner and T. Lewis eds.).Plenum Press, New York, pp. 305-316

Geoghiou, G. P. (1990). Overview of insecticide resistance.In Managing Resistance to Agrochemicals (M. B. Green,H. M. LeBaron and W. K. Moberg eds.)AmericanChemical Society Symposium Series 421, pp. $18-41$.

Gotoh, T. and Gomi, K. (2000).Population dynamics of Tetranychus kanzawai on hydrangea. Exp. Appl. Acarol. 24: 337-350.

Henderson, C.F. and Tilton E. W. (1955). Tests with acaricides against the brow wheat mite J. Econ. Entomol. 48:157-161.

Ho, C. C.A. (1990).preliminary study on the biological control of Tetranychus kanzawai in tea field by Amblyseius fallacis and Phytoseiulus persimilis (AcarinaTetranychidae, Phytoseiidae). (Chinese)Journal of Agricultural Research of China. 39: 2, 133-140.

Huang, P. K. Luo, X. N. Song, S. L.(1988).Control of Panonychus citri using Stethorus siphonulus Kapur in southeastern China. [Chinese]Acta Phytophylactica Sinica. 1988. 15: 1, 1-6. 8 ref.

Jiang, T. R. ; Zhang, L. B. and Wei, X. T. (1982).Biology of Stethorus punctillum Weise (Col.: Coccinellidae) and its utilisation. [Chinese]Natural Enemies of Insects. 4: 4, 34-36.

McMurtry, J.A. and Croft, B.A. (1997). Life-styles of phytoseiid mites and their roles in biological control. Annu. Rev. Entomol. 42: 291-321.

Opit, G. P.; Nechols, J. R. and Margolies, D. C. (2004).Biological control of twospotted spider mites, Tetranychus urticae Koch (Acari:Tetranychidae), using Phytoseiulus persimilis Athias-Henriot (Acari:Phytoseidae) on ivy geranium: assessment of predator release ratios.Biological Control. 29: 3, 445-452

Osman, M. A. (2000). Feasibilty of using some predaceous mites in biological control.M. Sc. Thesis, Fac. Agric., Mansoura Univ., Egypt.

Kishimoto, H. (2002). Species composition and seasonal occurrence of spider mites (Acari: Tetranychidae) and their predators in Japanese pear orchards with different agrochemical spraying programs.Appl. Entomol. Zool. 37: 603-615. 
Kishimoto, H. (2003).Development and oviposition of predacious insects, Stethorus japonicus (Coleoptera: Coccinellidae), Oligota kashmirica benefica (Coleoptera: Staphylinidae), and Scolothrips takahashii (Thysanoptera: Thripidae) reared on different spider mite species (Acari: Tetranychidae).Applied Entomology \& Zoology. 38: 1, 15-21.

Kitashima, Y. and Gotoh, T. (2003). Population dynamics of Panonychus osmanthi (Acari: Tetranychidae) on two Osmanthus species. Exp. Appl. Acarol. 29: 227-240.

Roy, M. ; Brodeur, J. and Cloutier, C. (2003).Effect of temperature on intrinsic rates of natural increase $(\mathrm{rm})$ of a coccinellid and its spider mite prey. BioControl. 48: 1, 57-72.

Sabelis, M. W. (1981).Biological control of two - spotted spider mites using phytoseiid predators. Part 1: Modelling the predator - prey interaction at the individual level.Agricultural Research Reports 910. Pudoc, Wageningen 242.

Shimoda, T., Shinkaji, N. and Amano, H. (1993). Seasonal occurrence of Oligota kashimirica benefica Naomi (Coleoptera: Staphylinidae) on arrowroot and effect of prey consumption rate on development and oviposition. Jpn. J. Appl. Entomol. Zool. 37:75-82 (in Japanese).

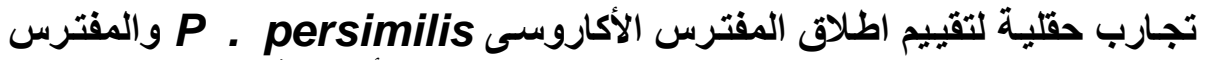

T. الحشرى S. gilvifrons urticae

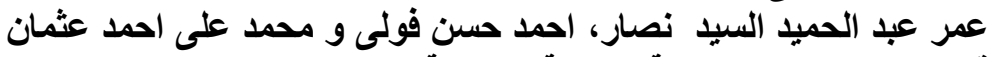
قسم الحيوان الزراعى- كلية الزراعة - جامعة المنصورة فئ فئ

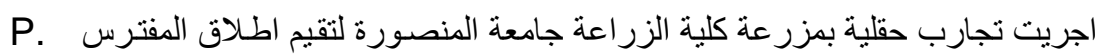

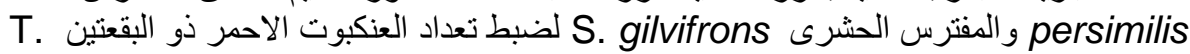
urticae

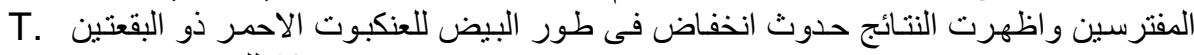
urticae

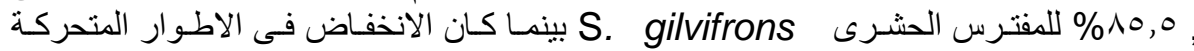

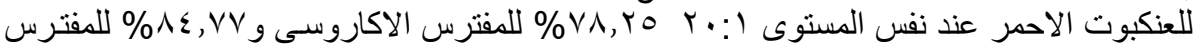
الحشرى بعد ب بو يوم من الاطلاق.
} 